\title{
Impact of Sleep on Medical Residents' Emotions: A Cross-Sectional Study Using a Wearable Device
}

Sarah El Baba, MD; Jumana Antoun, MD; Andrea Mladenovic, MD; Hani Tamim, PhD; Jihane Naous, MD

BACKGROUND AND OBJECTIVES: Controlling negative emotions and getting sufficient sleep are key factors in reducing medical errors and optimizing quality of care. The objective of this study was to measure the relationship between the emotions of medical residents and sleep as measured by a wearable device.

METHODS: We conducted a cross-sectional study addressing all residents of all postgraduation years and specialties at an Accreditation for Graduate Medical Educations-I accredited institution over 6 months. Sleep quantity and quality were measured by Fitbit Charge 2 device, and daily emotions by the Positive and Negative Affect Schedule questionnaire.

RESULTS: We included a total of 45 participants with a total of 1,112 observations (response rate $=19.3 \%$ ). The mean duration of total daily sleep was $5.9 \pm 1.6$ hours, with a deep sleep time of $1.1 \pm 0.4$ hours. We found a negative association between negative emotions and total sleep $\left(r_{r m}=-0.14, P<.0001\right)$ and deep sleep $\left(r_{r m}=-0.11, P=.0005\right)$ using repetitive measures correlation. A linear regression model to predict the negative emotions of the residents revealed additional determinants beyond deep sleep.

CONCLUSIONS: Our findings provide a further understanding of the importance of sleep quality on emotions by emphasizing deep sleep as a predictor of the second-day affect. Residency programs should strive to provide an ideal sleep environment to their residents and deliver workshops to deal with negative emotions.

(Fam Med. 2021;53(4):275-81.)

doi: 10.22454/FamMed.2021.173571

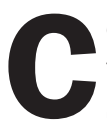
ontrolling negative emotions and getting sufficient sleep are essential to physicians' occupational wellness for reducing medical errors and optimizing quality of care. ${ }^{1-3}$ Medical residents, in particular, are subject to high levels of emotional exhaustion and sleep deprivation during their training years $, 4,5$ making them prone to mood disturbances and temper eruptions. ${ }^{6-8} \mathrm{~A}$ systematic review care professionals is well studied, there is a gap in understanding the effect of sleep on the daily emotions of health care workers.

Deep sleep is essential to restore cognitive functions and balance emotions, ${ }^{15}$ and low amounts of deep sleep may lead to worse moods. ${ }^{16}$ Previous research studies described mainly the duration and subjective quality of sleep of resident ${ }^{17-19}$ without tackling an advanced view of the sleep disturbances in terms of sleep stages and its consequences. To evaluate stages of sleep and awakenings, polysomnography remains the gold standard. However, it is impractical to be used in research due to its limitation to 1-day observation and the need of a laboratory. Actigraphy, coupled to a wrist-wearable pedometer, is a relatively inexpensive innovative instrument that can collect objective data on sleep quality for an extended period..$^{20,21}$

Accordingly, this study aimed to measure the relationship between medical residents' emotions and both total and deep sleep as measured by a wearable device. It also sought to describe the sleep quality among residents in terms of sleep stages and explore other nonsleep predictors of the negative emotions of the residents.

From the Department of Family Medicine (Drs El Baba, Antoun, Mladenovic, and Naous), and the Department of Internal Medicine (Dr Tamim), American University of Beirut, Lebanon. 


\section{Materials and Methods}

We conducted a cross-sectional study between May 2019 and November 2019 among medical residents of all postgraduation years (PGY) and specialties at the American University of Beirut (AUB) medical center in Lebanon. The residency programs are accredited by the International Accreditation Council for Graduate Medical Education (ACGME-I) and follow the US model of residencies. The study aimed to measure the relationship between sleep and emotions of residents by wearing a Fitbit for 1 month and filling the Positive and Negative Affect Schedule (PANAS) tool to describe their emotions every morning. The study was approved by the Institutional Review Board at AUB.

\section{Participants}

The study population included all the 300 medical residents at the AUB medical center. Recruitment occurred through email with three 2 -week interval reminders and posters displayed in the respective residents' lounges. Inclusion criteria included any medical resident at AUBMC for the academic year 2018-2019 of any postgraduate level or specialty. Exclusion criteria included not having a smartphone to download the Fitbit application. Those who volunteered to participate in the study contacted the research fellow, who arranged for a meeting where informed consent was signed, and the participants were briefed about the study details.

\section{Measures}

Baseline Questionnaire. The baseline questionnaire included a set of personal and sociodemographic characteristics that may influence emotions based on previous literature. These include age, sex, self-reported height and weight, marital status, number of kids, living status, specialty, current rotation(s), postgraduate year (PGY) level, and number of caffeinated beverages per day. Furthermore, it included the Buss-Perry
Aggression Questionnaire (BPAQ), the current gold standard to measure aggression. ${ }^{22} \mathrm{BPAQ}$ is a 29 -item, widely used, validated, self-rating scale that measures physical aggression, verbal aggression, anger, and hostility. Each item is rated on a 5-point scale of 1 (not characteristic of me) to 5 (very characteristic of me). When individual factor scores surpass the average cutoff, the individual will be considered to have a higher tendency for aggression. ${ }^{23}$

Measurement of Sleep. We measured sleep quantity and quality using the Fitbit Charge 2 device. It is a wearable wrist-based fitness tracker able to track daily physical activity and sleep (number and duration of awakenings, and stages of sleep). When compared to the gold standard (polysomnography), it was found to have a $96 \%$ and $75 \%$ accuracy to detect sleep and deep sleep, respectively. ${ }^{24}$ This device works by connecting via Bluetooth and transfers data to a mobile application. Participants were asked to wear the Fitbit on the nondominant wrist at least during the night for 1 month.

Measurement of Emotions. We used the PANAS to describe the daily participants' emotions. It is a selfreport, validated questionnaire that consists of 20 items to measure both positive and negative affect. ${ }^{25,26}$ Each item is rated on a 5-point scale of 1 (never) to 5 (always). Scores can range from 10-50 for both the positive and negative affects with lower scores representing lower levels of emotions.

Sample Size Calculation. Considering the reported negative correlation between sleep and aggression, ${ }^{27,28}$ we based sample size calculation on a Pearson correlation coefficient of -0.4, a significance level of .05, and power of $80 \%$. Using $\mathrm{MedCal}$ software, the number of residents needed to study the association was set at 46 . Assuming a $25 \%$ attrition rate, we set the sample size (n) at 64 medical residents.

\section{Data Analysis}

We conducted data analysis using SPSS software version 23 (IBM SPSS, Inc, Armonk, NY). We calculated descriptive statistics of baseline demographics, total sleep duration and sleep quality, BPAQ, and PANAS scores using means and standard deviation for continuous variables and proportions for categorical variables. Sleep metrics and emotions scores data were normally distributed.

We used multiple linear regression and correlations to study variables' associations. To account for intraindividual variations and different data points for the same participant, we used repeated measures correlation (RMCORR) to measure the association between total sleep (or deep sleep) and PANAS negative or positive emotions scores. RMCORR is a statistical technique that accounts for a within-individual association for paired measures assessed on two or more occasions for multiple individuals. ${ }^{29}$ Another common method is to average the repeated measured data for each participant before performing the correlation. To ensure rigorous findings, we performed both methods, and reached the same conclusions. RMCORR results are presented.

\section{Results}

A total of 58 participants were included in the study, for a response rate of $19.3 \%$. Due to dropouts and incomplete data, the final analysis included a total of 1,112 observations by 45 residents (Figure 1). Table 1 shows the demographics of the participants. The sample was almost split between males and females, with the majority being PGY1 (42.2\%), single (91.1\%), and living alone $(75.6 \%)$. The most common specialties were family medicine $(24.4 \%)$ and internal medicine $(20.0 \%)$. 
Figure 1: Flowchart of Participants Through the Study

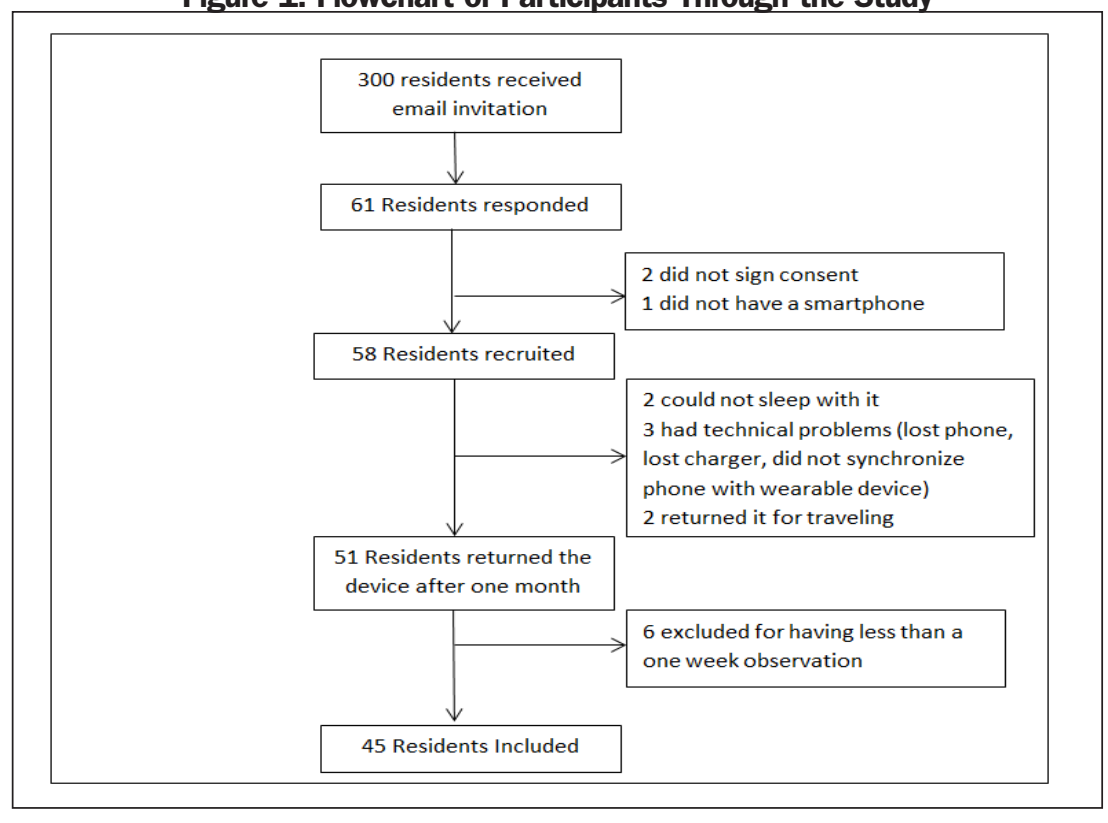

Table 2 describes the duration of the various stages of sleep and the scales of anger and emotions. The mean duration of total daily sleep was $353.4 \pm 96.9$ minutes $(5.9 \pm 1.6$ hours) with a deep sleep time of $67.6 \pm 24.7$ minutes ( $1.1 \pm 0.4$ hours). The reported subjective time of sleep was significantly lower than the time asleep recorded by the Fitbit (independent $t$ test, $P<$.0001). Almost onethird of the residents scored above the cutoff on BPAQ verbal aggression and hostility, while nearly twothirds scored above the BPAQ anger cutoff.

As for the correlation between the negative emotions and sleep, we found a negative association with total sleep $\left(\mathrm{r}_{\mathrm{rm}}=-0.14, P<.0001\right)$ and deep sleep $\left(\mathrm{r}_{\mathrm{rm}}=-0.11, P=.0005\right)$ using repetitive measures correlation. The correlation between sleep and negative emotions was not associated with sex, graduate-level, or specialty. Table 3 shows a multiple linear regression model to predict the negative emotions of the residents. Other nonsleep factors contributed to the prediction of negative emotions, including gender, consumption of caffeinated beverages, having kids, and graduate level.

\section{Discussion}

Sleep and Negative Emotions

Sleep is well recognized for its importance in the well-being of residents and performance ${ }^{1}$; however, this study aimed to explore the relationship between sleep and sleep quality on the daily emotions of residents. This study is unique as it utilized a wearable device-an objective tool-to measure sleep and sleep quality, while prior studies utilized subjective methods of sleep diaries and perception of quality of sleep., 4,17,19,30-32 Actigraphy was reported to be more accurate than sleep diary ${ }^{4,20,21}$; similarly, reported subjective time of sleep by our residents was significantly lower than the time asleep recorded by the Fitbit. The ACGME restricted work hours for residents to improve sleep hygiene and well-being ${ }^{33}$; nevertheless, this study has demonstrated that residents are sleep deprived with an average daily sleep of $5.9 \pm 1.6$ hours and a deep sleep of $1.1 \pm 0.4$ hours, values suboptimal to recommended total (7-9 hours) and deep sleep duration (1.5-2 hours). ${ }^{34,35}$ Furthermore, it supported a significant negative effect of total time asleep and quality of sleep on the residents' next-day mood. Our findings provide a further understanding of the sleep-emotion nexus by emphasizing deep sleep as an important predictor of the secondday affect.

\section{Emotions and Aggression}

Half of our sample scored higher than the average cutoff on the PANAS negative and positive emotions. Low mood states predispose residents to burnout and depression. ${ }^{11,12,31,36,37}$ Furthermore, emotional well-being is crucial to communicate effectively with patients, a competency set by the ACGME ${ }^{38}$ Alarmingly, one-third of the residents scored above the cutoff on verbal aggression and hostility, while more than two-thirds scored high on anger. Scientific reports discussing anger among graduates are scarce. ${ }^{39}$ Anger in residents is mainly reported through qualitative studies and reflective pieces. ${ }^{40,41}$ Residents are expected not to have high scores, as we found, since they are well educated and humanistic individuals who chose to be physicians. Our regression model has shown that hostility and anger were predictors of the negative emotions of residents. This relationship is an eye-opener about the need to educate the graduates about those feelings and how likely they are to impact their emotional health.

\section{Other Factors Affecting Emotions}

Nonsleep factors were found to be associated with negative emotions displayed by the residents. Similar to previous studies, depression, ${ }^{11,12}$ marital status, having kids, and living away from family were found to be associated with negative emotions. Being single and living with parents was shown to be protective against low mood during training years. ${ }^{11,12}$ Living with parents may spare residents from the time consumed doing home duties for the sake of rest and sleep. Our residents reported lower scores on negative emotions from one year to another. Transition throughout the training has an impact on the emotions of residents where less 
Table 1: Sample Characteristics ( $N=45)$

\begin{tabular}{|c|c|c|}
\hline Characteristics & \multicolumn{2}{|c|}{$\mathrm{M} \pm \mathrm{SD}$} \\
\hline Age (years) & \multicolumn{2}{|c|}{$27.84 \pm 2.6$} \\
\hline $\mathrm{BMI}\left(\mathrm{kg} / \mathrm{m}^{2}\right)$ & \multicolumn{2}{|c|}{$24.18 \pm 3.6$} \\
\hline Caffeinated beverages per day & \multicolumn{2}{|c|}{$2.1 \pm 1.5$} \\
\hline BPAQ & Male & Female \\
\hline Verbal aggression & $12.85 \pm 2.49$ & $12.85 \pm 2.32$ \\
\hline Hostility* & $18.82 \pm 3.69$ & $17.85 \pm 5.58$ \\
\hline \multirow[t]{2}{*}{ Anger** } & $15.99 \pm 3.37$ & $17.66 \pm 4.81$ \\
\hline & \multicolumn{2}{|c|}{ n (\%) } \\
\hline Sex female & \multicolumn{2}{|c|}{$21(46.7)$} \\
\hline Married & \multicolumn{2}{|c|}{$4(8.9)$} \\
\hline Having kids & \multicolumn{2}{|c|}{$1(0.02)$} \\
\hline \multicolumn{3}{|l|}{ Living Arrangement } \\
\hline Alone & \multicolumn{2}{|c|}{$24(75.6)$} \\
\hline With parents & \multicolumn{2}{|c|}{$11(24.4)$} \\
\hline \multicolumn{3}{|l|}{ PGY Level } \\
\hline PGY1 & \multicolumn{2}{|c|}{$19(42.2)$} \\
\hline PGY2 & \multicolumn{2}{|c|}{$4(8.9)$} \\
\hline PGY3 & \multicolumn{2}{|c|}{$11(24.4)$} \\
\hline PGY4 & \multicolumn{2}{|c|}{$6(13.3)$} \\
\hline PGY5 & \multicolumn{2}{|c|}{$3(6.7)$} \\
\hline PGY6 & \multicolumn{2}{|c|}{$2(4.4)$} \\
\hline \multicolumn{3}{|l|}{ Specialty } \\
\hline Family medicine & \multicolumn{2}{|c|}{$11(24.4)$} \\
\hline Internal medicine & \multicolumn{2}{|c|}{$9(20)$} \\
\hline Anesthesia & \multicolumn{2}{|c|}{$6(13.3)$} \\
\hline Pediatrics & \multicolumn{2}{|c|}{$4(8.9)$} \\
\hline Obstetrics-gynecology & \multicolumn{2}{|c|}{$4(8.9)$} \\
\hline Neurology & \multicolumn{2}{|c|}{$4(8.9)$} \\
\hline Radiation oncology & \multicolumn{2}{|c|}{$3(6.7)$} \\
\hline Pediatrics ICU & \multicolumn{2}{|c|}{$2(4.4)$} \\
\hline Radiology & \multicolumn{2}{|c|}{$1(2.2)$} \\
\hline Pathology & \multicolumn{2}{|c|}{$1(2.2)$} \\
\hline
\end{tabular}

${ }^{*} P<.05$, independent $t$ test.

$* * P<.01$, independent $t$ test.

Abbreviations: $\mathrm{M} \pm \mathrm{SD}$, mean \pm standard deviation; PGY, postgraduate year; BMI, body mass index; BPAQ, Buss-Perry Aggression Questionnaire; ICU, intensive care unit.

empathy and less negative emotions were reported as they pass from one postgraduate year to another. ${ }^{42-44}$ This could be attributed to the fact that interns are the most subject to hectic duties and sleepless nights.
From one year to another, residents get used to the hospital's ambiance and accept their role as physicians dealing with distressed patients.

\section{Limitations}

Our study should be interpreted in light of some limitations. While the sample size was met, the study was conducted in a single institution, which could affect the generalizability of the results. Moreover, 
Table 2: Quality of Sleep and Emotions of Residents

\begin{tabular}{|c|c|c|c|c|}
\hline $\begin{array}{l}\text { Daily Quality of Sleep M } \mathbf{E D D} \\
\text { (In Minutes) }\end{array}$ & Total $(n=45)$ & Male $(n=24)$ & Female $(n=21)$ & $P$ Value \\
\hline Time awake** & $50.0 \pm 21.2$ & $51.8 \pm 21.8$ & $48.1 \pm 20.4$ & $.004^{* *}$ \\
\hline Number of awakenings* & $23.6 \pm 11.0$ & $24.3 \pm 10.9$ & $22.83 \pm 11.09$ & $.028^{*}$ \\
\hline Total time in bed* & $403.1 \pm 110.2$ & $395.9 \pm 108.9$ & $411.13 \pm 111.27$ & $.022^{*}$ \\
\hline Minutes asleep & $353.42 \pm 96.9$ & $343.84 \pm 93.7$ & $363.82 \pm 99.35$ & .06 \\
\hline REM sleep*** & $77.0 \pm 30.4$ & $73.1 \pm 29.2$ & $81.38 \pm 31.22$ & $.000 * *$ \\
\hline Light sleep & $216.0 \pm 58.3$ & $212.11 \pm 56.5$ & $220.20 \pm 59.92$ & .26 \\
\hline Deep sleep & $67.6 \pm 24.7$ & $66.92 \pm 24.0$ & $68.4 \pm 25.5$ & .35 \\
\hline Subjective time of sleep ${ }^{* *}$ & $180.6 \pm 49.8$ & $175.8 \pm 39.0$ & $186 \pm 59.0$ & $.000 * *$ \\
\hline \multicolumn{5}{|l|}{ 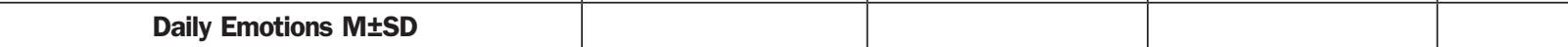 } \\
\hline PANAS negative emotions ${ }^{* *}$ & $15.2 \pm 5.6$ & $14.47 \pm 5.1$ & $16.03 \pm 6.1$ & $.000^{* * *}$ \\
\hline PANAS positive emotions* & $28.5 \pm 10.5$ & $27.82 \pm 10.8$ & $29.17 \pm 10.1$ & $.032^{*}$ \\
\hline \multicolumn{5}{|l|}{$\begin{array}{c}\text { Number of Residents Scoring } \\
\text { Above Cutoff, } \mathbf{n}(\%)\end{array}$} \\
\hline PANAS negative emotions & $23(51.1)$ & $12(50)$ & $11(52.4)$ & .890 \\
\hline PANAS positive emotions & $21(46.7)$ & $10(41.7)$ & $11(52.4)$ & .678 \\
\hline BPAQ verbal aggression & $14(31.1)$ & $5(20.8)$ & $9(42.9)$ & .196 \\
\hline BPAQ hostility & $13(28.8)$ & $7(29.2)$ & $6(28.6)$ & 1.000 \\
\hline BPAQ anger & $25(62.5)$ & $12(50)$ & $13(61.2)$ & .196 \\
\hline
\end{tabular}

$* P<.05$

*** $P<.01$ (independent $t$ test)

Abbreviations: $\mathrm{M} \pm \mathrm{SD}$, mean \pm standard deviation; PANAS, Positive and Negative Affect Schedule; REM sleep, rapid eye movement sleep.

Table 3: Predictors of Negative Emotions Using Liner Regression Analysis

\begin{tabular}{|l|c|c|}
\hline & $\begin{array}{c}\text { Negative Emotions } \\
\text { Coefficient (B) }\end{array}$ & $\boldsymbol{P}$ Value \\
\hline REM sleep & -0.015 & $.021^{*}$ \\
\hline Light sleep & -0.000 & .878 \\
\hline Deep sleep & -0.015 & $.039^{*}$ \\
\hline Caffeinated beverages & -0.338 & $.002^{* *}$ \\
\hline Sex & 1.143 & $.003^{*}$ \\
\hline Having kids & 5.182 & $.000^{* *}$ \\
\hline Postgraduate year & -1.159 & $.000^{* *}$ \\
\hline Anger & 0.180 & $.0002^{*}$ \\
\hline Hostility & 0.173 & $.001^{*}$ \\
\hline Verbal aggression & -0.180 & .015 \\
\hline $\begin{array}{l}R^{2} \\
\pm \text { SE }\end{array}$ & 0.167 & \\
\hline
\end{tabular}

$* * P<.05$

$* * * P<.01$.

Abbreviations: REM, rapid eye movement; SE, standard error of the estimate. surgery residents, who are known for having long duties and expected to have compromised sleep, were only represented by those who were enrolled from obstetrics-gynecology. This could be explained by the fact that wearing a wrist device could be cumbersome to scrubbing into the operation room when needed. Further, the Fitbit overestimates deep sleep duration and is accurate in detecting stages of sleep by $80 \%{ }^{24}$; therefore the observed association between deep sleep and the negative emotions may be underestimated. Accounting for daily reports of shifts, the number of working hours, and sleep habits before residency could have added substantial data to the study. However, asking for extra data could have affected the compliance to fill the daily PANAS, which were essential to our outcomes. 


\section{Conclusion}

As medical errors and quality of patient care are likely to be influenced by physicians' emotions, ${ }^{45}$ our findings suggest the importance of both the quantity and quality of sleep on the emotions of residents. Residency programs and hospitals should consider providing an optimal sleep environment to residents when on call to ensure a good sleep quality, and training workshops on emotional intelligence and dealing with negative emotions. Moreover, educating the residents about maintaining proper sleep hygiene whenever at home or in dorms is a one way to prevent emotional exhaustion.

CORRESPONDING AUTHOR: Address correspondence to Dr Jinane Naous, Department of Family Medicine, American University of Beirut.jn39@aub.edu.lb.

\section{References}

1. Panagioti M, Geraghty K, Johnson J, et al Association between physician burnout and patient safety, professionalism, and patient satisfaction: a systematic review and meta-analysis. JAMA Intern Med. 2018;178(10):1317-1331. doi:10.1001/jamainternmed.2018.3713

2. Motomura Y, Kitamura S, Oba K, et al Sleep debt elicits negative emotional reaction through diminished amygdala-anterior cingulate functional connectivity. PLoS One. 2013;8(2):e56578. doi:10.1371/journal. pone.0056578

3. Vandekerckhove M, Wang YL. Emotion, emotion regulation and sleep: an intimate relationship. AIMS Neurosci. 2017;5(1):1-17. doi:10.3934/Neuroscience.2018.5.1

4. Kalmbach DA, Fang Y, Arnedt JT, et al. Effects of sleep, physical activity, and shift work on daily mood: a prospective mobile monitoring study of medical interns. J Gen Intern Med. 2018;33(6):914-920. doi:10.1007/s11606-0184373-2

5. Rotenstein LS, Zhao Z, Mata DA, Guille C, Sen S. Substantial overlap between factors predicting symptoms of depression and burnout among medical interns. Journal of General Internal Medicine. J Gen Intern Med. 2020;810.

6. Hisler G. Aggressiveness and sleep: People with quick tempers and less anger control have objectively worse sleep quality. Iowa State University Capstones, theses Diss. 2016;15931.

7. Banks S, Dinges DF. Behavioral and physiological consequences of sleep restriction. J Clin Sleep Med. 2007;3(5):519-528. doi:10.5664/ jesm.26918
8. Kamphuis J, Meerlo P, Koolhaas JM, Lancel M. Poor sleep as a potential causal factor in aggression and violence. Sleep Med. 2012;13(4):327-334. doi:10.1016/j. sleep.2011.12.006. Internet.

9. Tomo A, De Simone S. Exploring factors that affect the well-being of healthcare workers. Int J Bus Manage. 2017;12(6):49. doi:10.5539/ijbm. v12n6p49

10. Verweij $H$, van der Heijden FMMA, van Hooff MLM, et al. The contribution of work characteristics, home characteristics and gender to burnout in medical residents. Adv Health Sci Educ Theory Pract. 2017;22(4):803-818 doi:10.1007/s10459-016-9710-9

11. Yousuf A, Ishaque S, Qidwai W. Depression and its associated risk factors in medical and surgical post graduate trainees at a teaching hospital: a cross sectional survey from a developing country. J Pak Med Assoc. 2011;61(10):968-973.

12. Zaman S, Rahim M, Khan A, et al. Prevalence of depression among post-graduate medical trainees: a multi-centre survey. BIRDEM Med J. 2014;4(1):18-21. doi:10.3329/birdem. v4i1.18548

13. Avidan AY. Sleep and fatigue countermeasures for the neurology resident and physician. Continuum (Minneap Minn). 2013;19(1 Sleep Disorders):204-222. doi:10.1212/01. CON.0000427205.67811.08

14. Rose M, Manser T, Ware JC. Effects of call on sleep and mood in internal medicine residents. Behav Sleep Med. 2008;6(2):75-88. doi:10.1080/15402000801952914

15. Walker MP. Sleep, memory and emotion. In: Progress in Brain Research [Internet]. Elsevier B.V.; 2010. p. 49-68. doi:10.1016/B978-0-444 53702-7.00004-X

16. Kecklund G, Åkerstedt T. Apprehension of the subsequent working day is associated with a low amount of slow wave sleep. Biol Psychol. 2004;66(2):169-176. doi:10.1016/j.biopsycho.2003.10.004

17. Kalmbach DA, Arnedt JT, Song PX, Guille C, Sen S. Sleep disturbance and short sleep as risk factors for depression and perceived medical errors in first-year residents. Sleep (Basel) 2017;40(3):1-8. doi:10.1093/sleep/zsw073

18. Slim E, Mattar M, Abi Rizk G. La qualité du sommeil chez les internes : étude transversale chez les internes à l'hôpital HôtelDieu de France (Liban). Pédagogie Médicale. 2014;15(1):31-42. doi:10.1051/pmed/2014007

19. Wali SO, Qutah K, Abushanab L, Basamh R, Abushanab J, Krayem A. Effect of on-callrelated sleep deprivation on physicians' mood and alertness. Ann Thorac Med. 2013;8(1):2227. doi:10.4103/1817-1737.105715

20. Louzon PR, Andrews JL, Torres X, et al. Characterisation of ICU sleep by a commercially available activity tracker and its agreement with patient-perceived sleep quality. BMJ Open Respir Res. 2020;7(1):1-5. doi:10.1136/ bmjresp-2020-000572
21. Campanini MZ, Lopez-Garcia E, RodríguezArtalejo F, González AD, Andrade SM, Mesas AE. Agreement between sleep diary and actigraphy in a highly educated Brazilian population. Sleep Med. 2017;35:27-34. doi:10.1016/j. sleep.2017.04.004

22. Schuetz CG. Using neuroimaging to predict relapse to smoking: role of possible moderators and mediators. Int $\mathrm{J}$ Methods Psychiatr Res [Internet]. 2008;17 Suppl 1(3):S78-82. Available from: doi:10.1002/mpr.247

23. Buss AH, Perry M. The aggression questionnaire. J Pers Soc Psychol. 1992;63(3):452-459. doi:10.1037/0022-3514.63.3.452

24. de Zambotti M, Goldstone A, Claudatos S, Colrain IM, Baker FC. A validation study of Fitbit Charge $2^{\mathrm{TM}}$ compared with polysomnography in adults. Chronobiol Int. 2018;35(4):465-476. doi:10.1080/07420528.2017.1413578.

25. Merz EL, Malcarne VL, Roesch SC, et al. Psychometric properties of Positive and Negative Affect Schedule (PANAS) original and short forms in an African American community sample. J Affect Disord. 2013;151(3):942-949. doi:10.1016/j.jad.2013.08.011

26. Thompson ER. Development and validation of an internationally reliable short-form of the Positive and Negative Affect Schedule (PANAS). J Cross Cult Psychol. 2007;38(2):227242. doi:10.1177/0022022106297301

27. Makinde O, Österman K, Björkqvist K. The Association between Sleep Deprivation, Aggression, and Antisocial Behavior in Adolescents in Ejigbo, Lagos, Nigeria. Eur J Interdiscip Stud. 2018;4(1):154. doi:10.26417/ejis.v4i1.p154-158

28. Semiz ÜB, Algül A, Ba冈oðlu C, et al. [The relationship between subjective sleep quality and aggression in male subjects with antisocial personality disorder]. Turk Psikiyatri Derg. 2008;19(4):373-381.

29. Bakdash JZ, Marusich LR, Bolin JH. Repeated Measures Correlation. Front Psychol. 2017;8(April):456. doi:10.3389/fpsyg.2017.00456

30. Zohar D, Tzischinsky O, Epstein R, Lavie P. The effects of sleep loss on medical residents' emotional reactions to work events: a cognitive-energy model. Sleep. 2005;28(1):47-54. doi:10.1093/sleep/28.1.47

31. Sen S, Kranzler HR, Krystal JH, et al. A prospective cohort study investigating factors associated with depression during medical internship. Arch Gen Psychiatry. 2010;67(6):557565. doi:10.1001/archgenpsychiatry.2010.41

32. Alami YZ, Ghanim BT, Zyoud SH. Epworth sleepiness scale in medical residents: quality of sleep and its relationship to quality of life. J Occup Med Toxicol. 2018;13(1):21. doi:10.1186/ s12995-018-0203-z

33. Vucicevic D, Mookadam F, Webb BJ, Labonte HR, Cha SS, Blair JE. The impact of 2011 ACGME duty hour restrictions on internal medicine resident workload and education. Adv Health Sci Educ Theory Pract. 2015;20(1):193203. doi:10.1007/s10459-014-9525-5 
34. Krystal AD, Edinger JD. Measuring sleep quality. Sleep Med. 2008;9(suppl 1):S10-S17. doi:10.1016/S1389-9457(08)70011-X

35. Hirshkowitz M, Whiton K, Albert SM, et al. National Sleep Foundation's sleep time duration recommendations: methodology and results summary. Sleep Health. 2015;1(1):40-43. doi:10.1016/j.sleh.2014.12.010

36. Moore KA, O’Brien BC, Thomas LR. "I wish they had asked": a qualitative study of emotional distress and peer support during internship. J Gen Intern Med. 2020;35(12):3443-3448. doi:10.1007/s11606-020-05803-4

37. Brielle M. Spataro, Sarah A. Tilstra, Doris M. Rubio and MAM. The toxicity of self-blame: sex differences in burnout and coping in internal medicine trainees. J Womens Health. 2012;25(11).

38. Arora S, Ashrafian H, Davis R, Athanasiou T, Darzi A, Sevdalis N. Emotional intelligence in medicine: a systematic review through the context of the ACGME competencies. Med Educ. 2010;44(8):749-764. doi:10.1111/j.13652923.2010.03709.x
39. Michels PJ, Probst JC, Godenick MT, Palesch $\mathrm{Y}$. Anxiety and anger among family practice residents: a South Carolina family practice research consortium study. Acad Med. 2003;78(1):69-79. doi:10.1097/00001888 200301000-00013

40. Fiscella K, Roman-Diaz M, Lue BH, Botelho R, Frankel R. 'Being a foreigner, I may be punished if I make a small mistake': assessing transcultural experiences in caring for patients. Fam Pract. 1997;14(2):112-116. doi:10.1093/fampra/14.2.112

41. Satterfield JM, Becerra C. Developmental challenges, stressors and coping strategies in medical residents: a qualitative analysis of support groups. Med Educ. 2010;44(9):908-916. doi:10.1111/j.1365-2923.2010.03736.x

42. Bellini LM, Shea JA. Mood change and empathy decline persist during three years of internal medicine training. Acad Med. 2005;80(2):164-167. doi:10.1097/00001888200502000-00013
43. Rosen IM, Gimotty PA, Shea JA, Bellini LM. Evolution of sleep quantity, sleep deprivation, mood disturbances, empathy, and burnout among interns. Acad Med. 2006;81(1):82-85. doi:10.1097/00001888-200601000-00020

44. Stucky ER, Dresselhaus TR, Dollarhide A, et al. Intern to attending: assessing stress among physicians. Acad Med. 2009;84(2):251-257. doi:10.1097/ACM.0b013e3181938aad

45. Mansukhani MP, Kolla BP, Surani S, Varon $\mathrm{J}$, Ramar K. Sleep deprivation in resident physicians, work hour limitations, and related outcomes: a systematic review of the literature. Postgrad Med. 2012;124(4):241-249. doi:10.3810/pgm.2012.07.2583 